\title{
Fight for subject confidentiality threatens disaster research
}

For nearly three months, Steven Picou, a sociologist at the University of Southern Alabama in Mobile, has been inundated with calls for his input on the Deepwater Horizon disaster. As the leader of what is probably the only long-term study on the human health effects of the 1989 Exxon Valdez oil spill, he has a unique-and not altogether encouragingperspective on the potential success of research on the new spill's effects on humans.

Researchers suspect that the Gulf oil spill may result in human health issues such as respiratory tract problems and DNA damage that may lead to cancer (J. Appl. Toxicol. 30, 291-301, 2010). However, the epidemiological studies needed to observe such effects might hit a roadblock in the form of subpoenas from lawyers looking for, among other data, the personal information of the study subjects.

"Anyone brave enough to try to conduct research needs to get ready," Picou says. "They'll have to fight in court to maintain the integrity of their work, including the privacy of the people they study."

Picou's perspective is shaped by the fact that shortly after the publication of his first papers on the sociological effects of the Valdez spill, he received a subpoena from Exxon lawyers for his data and the identities of his respondents.

Thanks to substantial legal support from his university, he challenged the requests, and, although he had to turn over most of his data, he kept the respondents' identities confidential.

and Southeast Asia.

Despite the new findings, neither GSK nor Merck have intimated plans to change their three-dose vaccine schedules.

"Based on all available study results, GSK currently believes three doses are optimal [for achieving] a high and sustained immune response," says Jennifer Armstrong, a GSK spokesperson. Merck spokesperson Jennifer Allen Woodruff adds, "our understanding of the immune response to Gardasil is that the third dose is important in terms of long term protection."

On the basis of their early results, both Kreimer and Dobson agree that altering the vaccine routine would be premature. "You have to be confident that you're not disadvantaging girls by giving them only two doses [of the vaccine]," says Dobson, who plans to continue to track antibody levels of the girls in his Canadian study for at least another year.
However, efforts to obtain the identities didn't stop, Picou says, and the burden of responding to requests brought his work to a halt for years. It's not clear what, if any, benefit these lawyers would have drawn from directly contacting the respondents. Picou suggests that companies or law firms allowed to contact individuals might try to intimidate them or coax them into joining litigation. At the very least, he says, it destroys any chance of getting unbiased data.

\section{Subpoena scare}

Even though epidemiological studies are commonly afforded the same protection as clinical trials under the Health Insurance Portability and Accountability Act (HIPAA), lawyers can still attempt to subpoena data, including identifying information, by making the argument that the benefit of disclosure outweighs the individual's right to privacy.

Nonetheless, it's an argument that, so far, hasn't succeeded in garnering private data when challenged, says Mark Frankel, director of the Scientific Freedom, Responsibility and Law program at the American Association for the Advancement of Science (AAAS) in Washington, DC. "While researchers often have to provide some of their research, I can't think of a case where a court has decided to hand over identifying information," he says. It's an easy argument to make, he notes, but one very difficult to win.

Still, the process can cost researchers and

\section{The cost of adult vaccines}

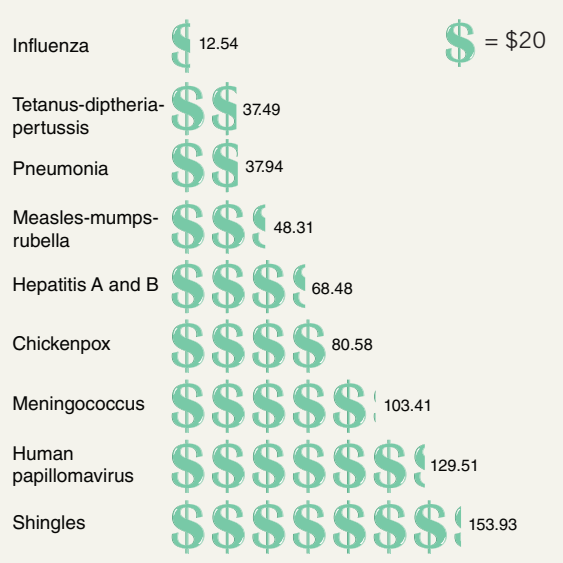

Private sector cost per dose $\mathrm{a}^{\mathrm{a}}$

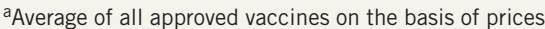
reported by manufacturers to the CDC.

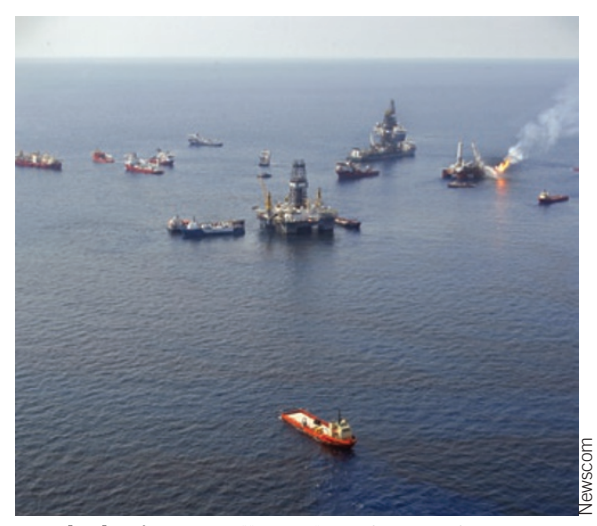

On the horizon: Spilling identifying information.

their supporting institutions years of work and hundreds of thousands of dollars in court costs. Often, Frankel says, the most devastating effect such requests can bring is an atmosphere of intimidation, sometimes causing researchers to abandon their work in favor of something less controversial.

There are certain steps, however, that an investigator can take to help make his or her defense of data easier, says Brad Racette, a neurologist at Washington University School of Medicine in St. Louis who has dealt with multiple subpoenas and Freedom of Information Act requests related to his work studying the health effects of toxin exposure in work settings. First and foremost, he says, researchers should be familiar with the requirements of their funding agencies. For example, work conducted for the US National Institutes of Health (NIH) must be held to strict confidentiality standards, and judges are often reluctant to defy such federal guidelines.

Sometimes, the NIH and other health agencies grant researchers 'certificates of confidentiality' meant to provide additional identity protection for their study subjects. These certificates, available under the Public Health Service Act, are used, most commonly, to protect the identity of illicit drug abusers who participate in scientific surveys and might otherwise be reluctant to disclose their illegal activity. The protection these confidentiality certificates provide is still up to the courts' discretion, however.

Ultimately though, Racette says, only legislation will keep litigation from being an extreme burden on sensitive types of research. Given that there is little to no political movement to support such legislation, researchers like those venturing to the Gulf coast would best be advised to consult with their institutions' attorneys before starting their work, he says. 